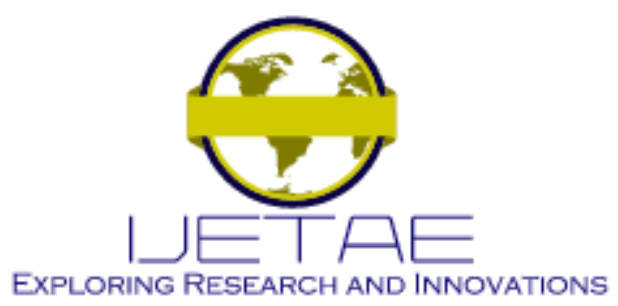

International Journal of Emerging Technology and Advanced Engineering

Website: www.ijetae.com (E-ISSN 2250-2459, Scopus Indexed, ISO 9001:2008 Certified Journal, Volume 11, Issue 12, December 2021)

\title{
Development of a Material for Gauging Sustainable Transitions Towards Adoption and Implementation of Television White Space Communications Systems
}

\author{
Hilario A. Calinao, $\mathrm{Jr}^{1}$, Lawrence Materum ${ }^{2}$, Junichi Takada ${ }^{3}$, Emmanuel Trinidad $^{4}$, Koji Homma ${ }^{5}$, Koji Ota ${ }^{6}$, \\ Saiful Amri Mazlan ${ }^{7}$, Shuib Rambat ${ }^{8}$ \\ ${ }^{1,2,4}$ De La Salle University, Manila, 0922, Philippines \\ ${ }^{1}$ Bulacan State University, Malolos, 3000, Philippines \\ 2, 5, 6, 7, ${ }^{8}$ Tokyo City University, Setagaya, 158-8557, Japan \\ ${ }^{3}$ Tokyo Institute of Technology, 152-8550, Japan \\ ${ }^{4}$ Don Honorio Ventura State University, Bacolor, 2001, Philippines \\ ${ }^{7,8}$ Universiti Teknologi Malaysia, Kuala Lumpur, 54100, Malaysia
}

\begin{abstract}
A television white space (TVWS) is an unused spectrum band in the TV broadcasting band. This unused band of frequency in TV channels can be used for different applications that benefit the people. TVWS, with its accompanying communications technologies, has promising uses and advantages in wireless systems. TVWS can replace or co-exist with other communications systems. However, gauging the technological transitions for the adoption of the TVWS system is sometimes overlooked. This paper developed a set of questions that could gauge and evaluate the level of adoption and implementation of a country's TVWS communications based on Davis's proposed technological transition architecture framework. The technological assessment developed in this paper leads to a better understanding of the niche, regime, and landscape considerations in implementing TVWS systems.
\end{abstract}

Keywords - Sustainable Transition, Systems Architecture, Technological Transition Television White Space

\section{INTRODUCTION}

\section{A. TVWS}

Radio spectrum is a valuable resource that delivers highvalue services for customers and citizens through communications engineering technologies. Unfortunately, the spectrum demand for innovative technology, services, and business opportunities is not synchronized with its supplies [1]. The radio spectrum is a limited resource that needs to be managed effectively to achieve its objective function, like frequency assignment based on the demand [2-5].
There are unused frequency channels in the television (TV) broadcast spectrum in terms of time or spatial usage. The unused frequency band that can be utilized for various wireless communications services is TV white space (TVWS) [6]. TVWS-based wireless communications techniques or technologies, e.g., Super WiFi [7], have many potentials to meet a particular country's demands for Internet access, machine-to-machine communications (M2M) monitoring services, smart metering, Internet-ofThings, and the like [8]. TVWS frequencies have many advantages in signal propagation. TVWS-based communications utilize very high frequency (VHF) and ultra-high frequency (UHF) spectrum bands. Since VHF and UHF have a longer wavelength than microwave bands, this advantage results in long-distance communications. These waves pass through certain obstacles like concrete and glass materials. This characteristic makes TVWS more attractive, not only for urban communications but also for rural communications applications [9]. From an economics standpoint, when the quality of connectivity improves in underserved areas of a country, it promotes growth and development, increases competitiveness, increases investment, and improves the ease of doing business [10 12]. Albeit decreasing a TV broadcast's protection contour by lowering its transmitted power can free up the TV spectrum by $30 \%$, another way to do so is to switch to a low-power, low-tower single frequency network, which can free over $60 \%$ of the spectrum used for television [13]. However, one of the keys to TVWS, aside from having a geolocation spatial database, is for measurements to be done in time and spatial scales $[14,15]$. 


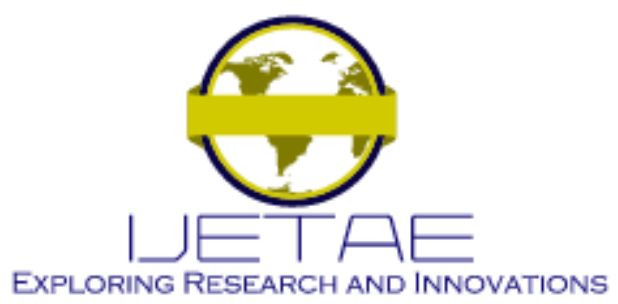

International Journal of Emerging Technology and Advanced Engineering

Website: www.ijetae.com (E-ISSN 2250-2459, Scopus Indexed, ISO 9001:2008 Certified Journal, Volume 11, Issue 12, December 2021)

Moreover, TVWS plays a vital role in mobile broadband applications, which are expected to exceed three billion worldwide. Mobile broadband accommodates the exponential increase in traffic demand in the radio spectrum [16]. TVWS communications can improve the frequency spectrum usage, but its availability varies from one location to another [17]. White space primary users are TV services, and the secondary users are the white space devices (WSD) [18].

Several TVWS communications standards [19-25] have also been developed and released. For example, the IEEE802.22 standard [23] allows reusing the unused channel in VHF and UHF provided that it does not interfere with the used channels. It also describes the type of modulation used in TVWS communications and its transmission parameters. Its protocol considers contiguous and non-contiguous channel spectrum management [26]. It uses cyclic prefix - orthogonal frequency division multiplexing (CP-OFDM). CP-OFDM has been used in other wireless standards and adopted in the market through the popularity of $\mathrm{WiFi}$. However, the use of it in managing the interference when spectrum agility is needed is difficult. In comparison, block filtered OFDM (BF-OFDM) proved good spectral confinement, reconfigurable structure, and simple receiver, has been [27].

The Long-Term Evolution (LTE) standard was developed as a fourth-generation mobile technology. Due to the fast-changing demand in data access, simulations and laboratory testing proved that LTE technology with cognitive radios is achieved in TVWS [28,29]. Cognitive radio can modify its response and behavior based on external factors like observations on the spectrum [30].

\section{B. Industry-Government TVWS Communications Collaboration}

TVWS communications have promising applications and usages, but it has many considerations before its full deployment. Some considerations are radio regulations for white space communications, white space database (WSDB) specifications and operational guidelines, requirements, category, and specifications of white space devices[18]. It is also essential to understand the differences between regulations and their rationale so that better WSDs can be designed to meet the needs of various regions and applications [9]. Both the industry and government authorities have to work hand in hand to implement and deploy TVWS communications. An example is a joint venture between Singapore and Siemens.
They developed WhiteRange radios, also known as TVWS for Super WiFi, which has three components: the TVWS gateway node that serves as gateway access, the TVWS concentrator node that functions as an access point, and the TVWS end node that serves as a client or station [7]. Through government and industry cooperation, the manufacturer of the WSDs embeds the spectrum regulation policy as part of the firmware on every application-specific radio they produce. Changing the specific spectrum policy requires pre-approval and re-application in the radio. A WSD with policy-based spectrum access is more flexible than the direct-encoding of spectrum policy [31]. Nevertheless, some parameters specified on the license change over time, like transmit power, bandwidth used by the system, carrier frequency, location of the radio, and other parameters [5].

For creating an effective policy for TVWS communications, it is crucial to consider the structure of systems that need to be changed. The policy creation must consider current environmental policy, culture, economic impact [24] [12,32]. The United States' Federal Communications Commission (FCC) was the first to develop the TVWS regulations in 2008 and showed regulation improvements in 2010, 2012, and 2015. Ofcom collaborated with the European Telecommunications Standards Institute (ETSI) also released its TVWS regulations in 2015 [33]. ETSI also released WSD wireless access systems operating at a TV broadcast band of $470 \mathrm{MHz}$ to $790 \mathrm{MHz}$ bands [34].

\section{Pathways to Sustainability Transitions}

To give a gist of the concept of sustainability transitions, consider Figure 1. It shows a multi-level perspective on transitions that happen at three levels. These are landscape (macrolevel), regime (mesolevel), and niche (microlevel) [35]. Landscape-level refers to the topmost realm in which niches and regimes exist. It is composed of slow-changing elements such as macroeconomic, demographic, cultural, and political situations and significant events. Regime level concerns the prevailing combinations of practices, rules, and technologies (e.g., engineering practices, infrastructures, and industrial and governing institutions). The niche level deals with specific innovation, experimentation, and technology applications and is protected from market and regulation forces. The niche level provides areas for experimenting with new technologies to explore the technology's benefits, limitations, and potential applications [26]. 


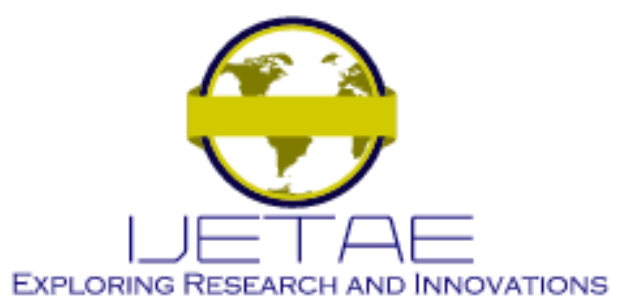

International Journal of Emerging Technology and Advanced Engineering

Website: www.ijetae.com (E-ISSN 2250-2459, Scopus Indexed, ISO 9001:2008 Certified Journal, Volume 11, Issue 12, December 2021)

Each level has actors or agents that interact in different ways. These agents can be the government, market or industry, and civil society.

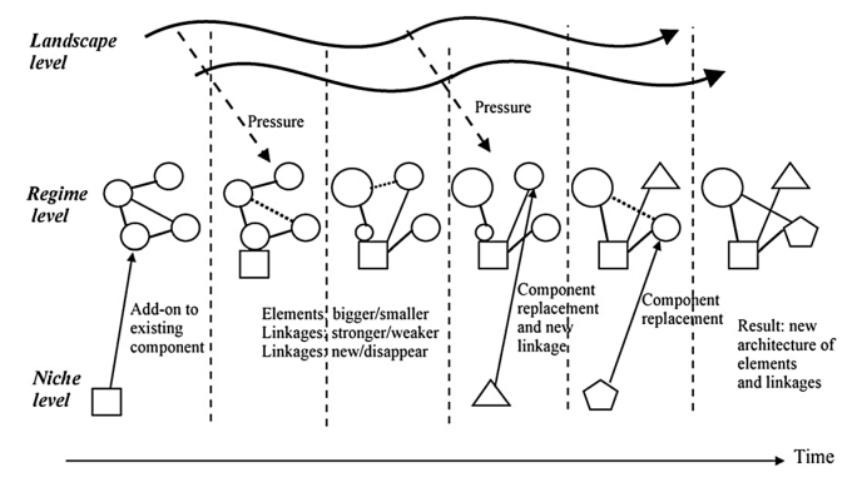

Figure 1. Pathways to sustainability transitions from [36].

The government regime for wireless services must evaluate its policy instrument for new entrant restrictions, device transmitted power limits, and the device's ability to reduce interference. When these three aspects are inadequately set, it can cause welfare loss [37].

TVWS communication is in its early stages of development in several countries around the world. There are pilot projects that took place in different areas. If their deployment stages are evaluated, appropriately assessed, and established, several demands for connectivity can be addressed. TVWS systems are considered on their technological niche stage in other countries, while others are on the socio-technical regime stage. Some are in the more developed socio-technical landscape.

The technological niche is the stage where innovations emerge but in its low performance and unstable sociotechnical configurations. At this stage, the technology is initially developed and operated by a small network. This stage is also for the experimentation of the new technology to determine its benefits and limitations[38]. Temporarily, technology in a niche stage is on protective space to set up, configure, and develop such innovation. This protection can eventually decline progressively as the innovations compete with regime technology [39].

In comparison, the socio-technical regime is the stage where broader communities are aligned based on the activities [36]. It is a more established stage due to users' technological adoption and skillsets, engineering practices, political settings, industry, and infrastructure [40].
The socio-technical landscape stage of technology is beyond the effect of the niche and regime stage. Technology in the landscape stage took decades to change. Slow-changing factors contributing to changes in the sociotechnical landscape include cultural biases, limiting economic conditions, shifting political settings, or changing market conditions $[36,40]$. The changes from one sociotechnical regime to another are called transitions [36].

Symbiotic technology serves as an add-on to the regime and co-exists or complements without disrupting the existing technology's basic architecture. It is used to solve local problems and improve performance, but economic considerations usually drive these adoptions. However, technological substitution can replace the entire technology with another technology [36]. When the technology is expected to improve social and economic conditions, it is vital to determine and understand risks before adopting it [41]. There are two methods to manage the risk; the first is the decision model with uncertainties and risk, and the second is the real options model. The risk is evaluated with its required and expected value in the decision model, or it can be projected as a probability distribution. In the real options model, it involves the careful design of the priority access, the value of the options, implementation, and its impact are important considerations [42]. It is also essential to develop a program that informs a broader community about the risk through lectures, training, and workshops [43].

\section{Spectrum Policies and Focus of the Work}

The policy established controls the spectrum [12]. In America, access to the spectrum significantly increased in the past years due to the emergence of technology in smartphones, gadgets, and other mobile devices, which require spectrum access. The United States perceives that spectrum management plays a significant role in economic growth and technological advancement $[44,45]$.

Spectrum management practice may also be considered to enhance the allocation and improve its technical efficiency, which focuses on a mixed regulatory regime. The efficiency is achieved dynamically by consolidating and simplifying spectrum usage rights and incentivizing spectrum licensee holders in public sectors and communities in exchange for its unused portion in the spectrum [46]. It is also important to have technological promotions aside from transaction efficiency because it significantly affects spectrum usage utilization [47]. 


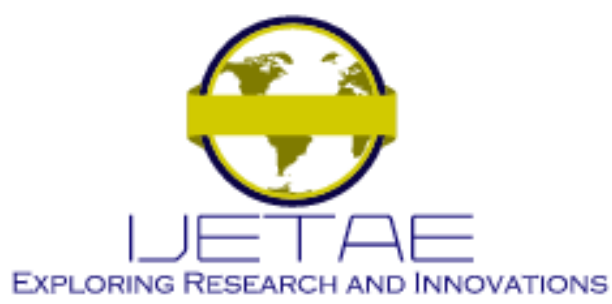

International Journal of Emerging Technology and Advanced Engineering

Website: www.ijetae.com (E-ISSN 2250-2459, Scopus Indexed, ISO 9001:2008 Certified Journal, Volume 11, Issue 12, December 2021)

In Europe, license shared access (LSA) arrangements in the frequency spectrum are encouraged. With this kind of innovation, a shared access arrangement gives the new entrants opportunity, increasing the spectrum's affordability because of the increased competition, thus lowering the cost for the customer. However, LSA may alter the traditional market because it is seen as radical innovation for such communications network operators [16,45]. However, there must be an agreement on general sharing conditions at the European level [48]. The LSA seems to have more dynamics and flexibility in managing the spectrum, enabling mobile virtual network operators to integrate [49]. However, the dynamic spectrum access technique also has advantages in machine-to-machine communications because of its energy efficiency and low communications protocol overhead [8].

Despite spectrum policies, transformative changes happen. Such changes deal with strategic challenges, like supply and demand, changing innovation systems, climate change, and resource depletion. In contrast, the multi-level perspective deals with long-term processes of transformative change [50]. The innovation system approach focuses on the importance of refining the firm's innovation capabilities and the settings that secure them. Moreover thus, the innovation system approach can also be considered in transitional studies in the policymaking framework.

Non-technological regulations can also provide valuable inputs in making innovation policy. The management work involves organizational structure relationships, the organization's size and compliance, external firms' management, and even the new product's pricing [51]. External environmental factors like marketplace trends, competitions, and societal conditions influence internal environmental factors [52].
This paper focuses on gauging the technological adoption and implementation of a TVWS communications system of a country by presenting a survey material/tool developed by the authors. It can be used as a tool by TVWS operators, businesses, conglomerates, and telecommunications companies to assess the implementation of TVWS communications in their country. This tool is also applicable to the TVWS system in the regime stage to assess feedback from different technology stakeholders. Moreover, it can also be used in the TVWS system in the landscape stage to evaluate people's acceptance of the technology. It is used to measure the levels of implementation of TVWS communications that need further assessment that possibly overlooks some aspects by policymaking bodies of the country, government agencies, and the public. The tool can benefit the TVWS operators of the country that is currently implementing this technology.

This paper is organized then as follows. Section 2 discusses the TVWS in different countries. Section 3 focuses on how the material was developed and made. Section 4 discusses the content of the material, and Section 5 is the conclusion.

\section{TVWS IN DIFFERENT COUNTRIES}

Several countries around the world adopted TVWS communications. Table 1 shows the different countries around the world that conducted pilot projects and their implementation highlights. Singapore, Japan, and the Philippines are countries in Asia that conducted their TVWS projects with their own applications. There are also five countries in Africa, two in Europe, two in North America, and two in South America with their own TVWS project implementations. 


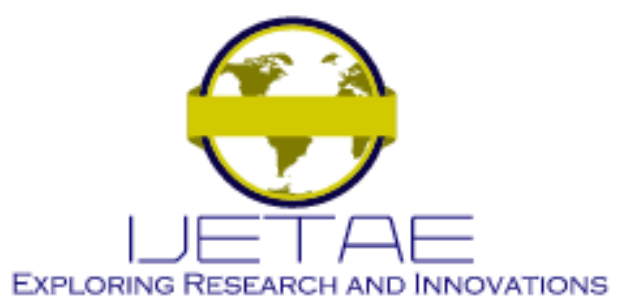

International Journal of Emerging Technology and Advanced Engineering

Website: www.ijetae.com (E-ISSN 2250-2459, Scopus Indexed, ISO 9001:2008 Certified Journal, Volume 11, Issue 12, December 2021)

TABLE 1

OVERVIEW OF TVWS PILOT PROJECTS [53] [54]

\begin{tabular}{|c|c|c|c|}
\hline Continent & Country & Projects & Highlights \\
\hline \multirow[t]{6}{*}{ Asia } & Bhutan & Remote healthcare & Unlimited by terrain \\
\hline & \begin{tabular}{|l|} 
Philippines \\
\end{tabular} & \begin{tabular}{|l|} 
Enhanced fishery activities, \\
VSAT backhaul connections \\
for disaster management
\end{tabular} & $\begin{array}{l}\text { 3-4 km transmission } \\
\text { Cost-effective }\end{array}$ \\
\hline & Japan & $\begin{array}{l}\text { Disaster management } \\
\text { communication }\end{array}$ & $12.7 \mathrm{~km}$ transmission \\
\hline & Taiwan & $\begin{array}{l}\text { Broadband for ecosystem } \\
\text { tourism }\end{array}$ & $\begin{array}{l}-10 \mathrm{~km} \\
\text { transmission }\end{array}$ \\
\hline & Singapore & $\begin{array}{l}\text { Small cell backhaul and } \\
\text { video surveillance }\end{array}$ & $\begin{array}{l}\text { TCP/IP speeds of } 20 \\
\text { Mbps @ } 40 \mathrm{~m} \\
\text { indoor NLOS }\end{array}$ \\
\hline & Mozambique & $\begin{array}{l}\text { Online libraries and rural } \\
\text { online schooling support }\end{array}$ & $\begin{array}{l}\text { Possibility of free } \\
\text { rural internet access }\end{array}$ \\
\hline \multirow[t]{4}{*}{ Africa } & Botswana & Telemedicine & $\begin{array}{l}\text { Support for VoIP } \\
\text { and Video over IP }\end{array}$ \\
\hline & Namibia & $\begin{array}{l}\text { Large-scale TVWS internet } \\
\text { rollout }\end{array}$ & $\begin{array}{l}\text { Targets a coverage } \\
\text { area of } 9,424 \mathrm{~km}^{2}\end{array}$ \\
\hline & Tanzania & $\begin{array}{l}\text { Commercial feasibility of } \\
\text { TVWS }\end{array}$ & $\begin{array}{l}\text { Goal to reach more } \\
\text { than } 74,000 \text { students } \\
\text { for access } \\
\end{array}$ \\
\hline & Kenya & \begin{tabular}{|l|} 
Complimentary technology \\
to license-exempt bands at \\
$13 \mathrm{GHz}, 5 \mathrm{GHz}$, and $2.4 \mathrm{GHz}$
\end{tabular} & $\begin{array}{l}14 \text { km PMP link, } 2.5 \\
\text { EIRP @ } 16 \text { Mbps } \\
\text { over } 8 \text { MHz TV } \\
\text { bands }\end{array}$ \\
\hline \multirow[t]{2}{*}{ Europe } & Britain & $\begin{array}{l}\text { Diffusion of LTE into } \\
\text { TVWS using the } 802.11 \text { af } \\
\text { standard, resulting in } 45 \\
\text { Mbps in FDD mode (20 } \\
\text { MHz each for uplink and } \\
\text { downlink) via channel } \\
\text { aggregation and } 19 \text { Mbps in } \\
\text { TDD mode via the } \\
\text { aggregation of } 3 \mathrm{TV} \\
\text { channels }\end{array}$ & $\begin{array}{l}3.7 \mathrm{~km} \text { point-to-point } \\
\text { link using } 1 \mathrm{TV} \\
\text { channel }\end{array}$ \\
\hline & Scotland & Smart city project & TVWS sensors \\
\hline \multirow[t]{2}{*}{$\begin{array}{l}\text { North } \\
\text { America }\end{array}$} & $\begin{array}{l}\text { Seattle, } \\
\text { Washington }\end{array}$ & $\begin{array}{l}\begin{array}{l}\text { Faster Internet than existing } \\
\text { technology }\end{array} \\
\end{array}$ & $\begin{array}{l}\text { Focused on speed } \\
\text { and coverage }\end{array}$ \\
\hline & $\begin{array}{l}\text { Washington } \\
\text { County, Maine }\end{array}$ & $\begin{array}{l}\text { Transmission of TVWS in } \\
\text { difficult rural, semi-rural, } \\
\text { and urban environments }\end{array}$ & $\begin{array}{l}\text { NLOS PMP link of } \\
5-8 \mathrm{~km} \text { with a data } \\
\text { rate of } 10 \mathrm{Mbps}\end{array}$ \\
\hline \multirow[t]{2}{*}{$\begin{array}{l}\text { South } \\
\text { America }\end{array}$} & Uruguay & $\begin{array}{l}\text { Connectivity for rural } \\
\text { schools }\end{array}$ & $\begin{array}{l}\text { TVWS hardware } \\
\text { technology diffusion }\end{array}$ \\
\hline & Jamaica & $\begin{array}{l}\text { High-speed internet } \\
\text { connectivity }\end{array}$ & $\begin{array}{l}\text { Broadband in a } \\
\text { marine ecosystem }\end{array}$ \\
\hline
\end{tabular}

The pilot project must comply with regulations before proceeding with full-pledge implementation. After research and development, it must conduct standardization or comply with adopted standards before pilot projects and trials. However, when some parts or phases need change or are missing, the regulations may be modified. Implementing white space communications has lots to consider, including the operational frequency band and its regulations, the white space database, and the air interface used by WS communications [18,55].
The TVWS air interface at the physical and link layers enables the transmission and reception of wireless signals. TVWS connectivity providers must comply with the adopted wireless standards for manufacturers to reduce the cost of wireless units at a mass scale, increase the number of suppliers that produce the units, and increase the number of application fields [18]. One of the most considered challenges in wireless communications is high penetration loss inside the building and multipath fading. Multipath fading does occur in TVWS communications. To further increase its target, TVWS transceivers via cooperative communications have been proposed. This technique relies on relaying a weak signal using another node, improving link quality and overall network capacity [56]. Thus, the area coverage and data throughput of the TVWS can be increased not only by transmitted signal power and bandwidth [57].

The coexistence of two access methods to the same frequency in an unlicensed spectrum affects their performance. A study on the effects of WiFi and licensedassisted access (LAA) on the same frequency band shows that WiFi's performance degraded more deeply than LAA performance. The study also shows that the WiFi performance can be improved, but the LAA performance is slightly affected [58]. Interference is observed during the combined testbed designed with WSD and digital video broadcasting-terrestrial (DVB-T) receiver. Interference was observed in DVB-T channels due to WSD operating in the same channel and the adjacent channel [59].

TVWS availability in a particular area of a country needs to be evaluated first before establishing regulations to operate in the future [60]. Other countries like Ireland and Switzerland have grown their economy but differ in the aspect of innovation rates. This disparity is due to the different focus of innovation. Ireland shows favorable rates in process innovation but adverse effects on product innovations, while Switzerland positively affects product innovations [61].

Although TVWS regulations exist in several countries, it depends on jurisdiction based on the needs, circumstances, and engineering resources [33]. Examples are the construction of towers used for communications antenna and acquisition issues vary in different countries [62].

\section{A. TVWS in Singapore}

Through Telecommunication Standards Advisory Committee (TSAC), the Singapore government released a technical standard with recommendations on specifications and TVWS equipment requirements. 


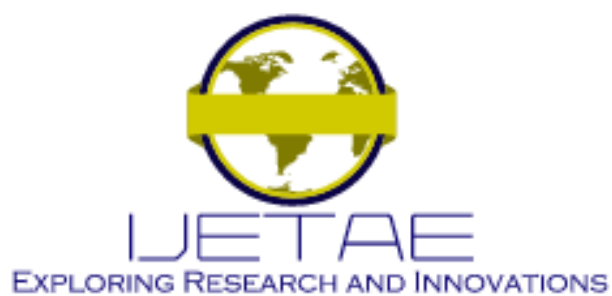

International Journal of Emerging Technology and Advanced Engineering

Website: www.ijetae.com (E-ISSN 2250-2459, Scopus Indexed, ISO 9001:2008 Certified Journal, Volume 11, Issue 12, December 2021)

White space devices shall not cause harmful effects on other radio communications services. It is also designed in compliance with the International Commission on Nonionizing Radiation Protection guidelines. The TVWS equipment registration must be under the registration scheme of the Infocomm Media Development Authority General Equipment Registration. Moreover, to access the TVWS geo-location database, the interested companies need to apply for a Service-Based Operator license. Singapore has three approved database providers for TVWS: Network Genetics Pte Ltd., Starhub Ltd, and DNNA Solution Pte. Ltd. [6,63]. The geo-location database also solves the issues of unauthorized use of the spectrum [12].

TVWS systems applications in Singapore are used in smart grid, safety and security, surveillance, smart building, and intelligent transport systems. It is also used in a diversity of links which acts as an independent backup link for fiber. TVWS communications links are cheaper compared to fiber.

In Singapore, a high-priority channel (HPC) utilizing the TVWS channels is proposed. Unlicensed WSDs use the HPC to increase the revenue of the WSDB providers. The more WSD is utilizing the HPC, and the more revenues are created. This situation is possible by lowering the utilization price of HPC, which attracts more WSD users [64]. Since payment is in the spectrum, utilization does not affect the performance of the firm. Besides, the spectrum payment does not increase the value of the mobile industry [65]. Price data can be analyzed by contract type and the operators [66].

\section{B. TVWS in Japan}

TVWS system pilot projects in Japan were used for disaster management communication jointly conducted with Hitachi Kokusai Electric. This project is a point-topoint over long-distance communications up to $12.7 \mathrm{~km}$ line-of-sight [17]. There are also fixed point-to-multipoint trials taken for rural broadband access. Other TVWS communications systems applications include rural broadband access, smart utility/ machine-to-machine sensor network, public-government services, home wireless access, public safety, and mobile communications [67]. Even though many trials have been conducted, there is no development of white space communications equipment. One reason is that the price of the WS radio equipment must be affordable. The manufacturer should produce lowpriced WS radio equipment to make it affordable to millions of expected users.
Another reason is that the equipment must be compliant with the standard set by the regulators. The National Institute of Information and Communications Technology developed a WS communications equipment prototype compliant with IEEE 802.11af, IEEE 802.22, and IEEE $802.15 .4 \mathrm{~m}$ [18]. The next step is to identify different issues and check the feasibility of different scenarios according to the country's demands and circumstances. Considering the radio regulations and business deployment are also important [17].

\section{TVWS in the Philippines}

Through the National Telecommunications Commission (NTC), the Philippine government allowed the unassigned and unused allocated TV broadcast channel for private and public utilization. The purpose of this policy is to improve and extend the basic telecommunications service in the unserved areas. Thus, NTC disseminated rules on utilizing the unassigned TV broadcast channels. First, the unassigned and unallocated TV broadcast channels are to be used for TVWS communications. Second, the NTC type and approved radio equipment are authorized for TVWS operations. Third, the NTC appropriate registrations, permits, licenses, and fees need to be secured. Fourth, there must be a technical working group composed of the representatives from the Department of Information and Communications Technology (DICT), Kapisanan ng mga Brodkaster $n g$ Pilipinas (Society of Philippine Broadcasters), and NTC must be created [68].

Based on the third quarter of 2016, the average connection speed utilizing IPv4 in the Asia-Pacific region, the Philippines average data rate was $4.2 \mathrm{Mbps}$, at 103rd at the global rank. While Singapore had 18.2 Mbps that ranked sixth, and Japan had 18.0 Mbps that ranked seventh. Spectrum management in the Philippines is an administrative approach which is sometimes called a beauty contest approach. However, this administrative approach is criticized because of its lack of transparency. An auction approach is recommended as the most effective and transparent allocation of the spectrum [69]. The Philippines suffers from inefficient broadband telecommunications services. There are lots of issues that need to be addressed. One issue is a high concentration of the incumbent industry player's market, making the new entrants challenging to enter. The cost of the network backbone is high. Moreover, the policy scheme or framework in telecommunications regulations is outdated. 


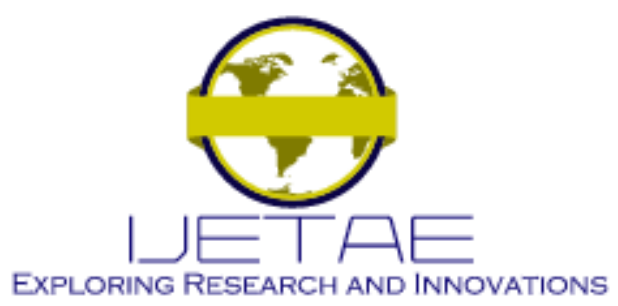

International Journal of Emerging Technology and Advanced Engineering

Website: www.ijetae.com (E-ISSN 2250-2459, Scopus Indexed, ISO 9001:2008 Certified Journal, Volume 11, Issue 12, December 2021)

Also, the inactive implementation of regulations contributes to the broadband telecommunications service issues [11]. The use of TVWS is being expected to address several of these connectivity concerns.

Department of Science and Technology invested \$5M for a pilot run in Bohol, Philippines [70]. This TVWS project deployment is the largest in Asia. This project was expected to enhance fishery activities and also for VSAT backhaul connections for disaster management. TVWS is also planned for public services such as eHealth, eGovernment services, environmental sensors for PAGASA and DOST project NOAH, Internet access in public places, local government units, national agencies, hospitals, and educational institutions facilities, and healthcare centers [70].

Through DICT, the Philippine government states that the success of TVWS communications can be replicated to provide Internet access in a broader range. The government can now provide broadband access to remote areas of the country. However, it must ensure that TVWS communications must be accessible to the public and private without any issue of interference [71].

\section{SUSTAINABILITY TRANSITIONS FOR TVWS}

The technological transition must be managed because there are challenges and opportunities related to a vested interest, intolerance, group behavior, lock-in to undesirable technologies, and low-speed access to information [72]. Since technology impacts society, and society also influences technology [73].

Transitions occur with lots of conflicts that can be encountered during the process. During the process, the vision, objectives, and means are changed over time. The transitions create controversy, which attracts public, economic, and political interest [74]. During the transition, the management must be delicately involved to solve the conflict between long-term ambition and short-term concerns. Transition management supports creating better and legitimate public policy, which could also pave the way to solve society's problems [75].

In transition management, systems engineering plays a vital role in executing implementation plans. It provides a means that can help facilitate the discussion between transition management research communities. Systems engineering provides development tools and methods to execute systems transition [38]. During the transitions, the user of technology must be deeply involved in effectively integrating the technology into the complex systems[76].
Technological transition thinking involves intensive systems thinking approach to study the socio-technical transitions literature, framework, and approaches. Management of technology determines the opportunities and challenges the product, process, and infrastructure face while maintaining its market position and improving business performance concerning its objectives [77].

For having a flexible system policy, transition management must be a continuous process. The system's methodology must be evaluated intensively to provide necessary information and indicators to become references for policy making[32,78].

Due to continuous wireless network changes, the reconfigurable network must be included in the planning procedure [79]. Flexible planning of wireless networks like the TVWS communications system may also be required.

In spectrum management, the government must be aligned with its objectives with the private sectors' objectives. The market cannot deliver all the necessary services and task demands because it depends only on its infrastructure and dedicated allocations. The government needs to initiate an assessment of the requirements to meet the demand with an academic community's help to all interested parties. Moreover, it must be clear and provide technological advancement complied with the standards. It is essential to build trust among the stakeholders to share the spectrum. This trust builds a new spectrum arrangement sharing for the new technology [80]. There is also an arrangement contract between a third party reserving the spectrum from the TV licensee to resell it to WSDs [81]. The government may also form an external entity of public and private groups responsible for decision-making and transition management [75].

A management system capable of pulling the external resources of innovation to adapt to the rapid change in environmental operations and emphasizes internal research and development work can become more successful in creating sustainable, innovative capabilities for continuous growth [82,83]. However, not all businesses benefit from research and development. The businesses involving hightechnology are benefited the most while low-technology industries are less benefited in R\&D [83].

Sustainable transition is a long-term fundamental transformation process focusing on the multi-level perspective established on socio-technical system change to sustain production and consumption. The sustainability of transition is complex due to diverse interested actors involved in the processes $[84,85]$. 


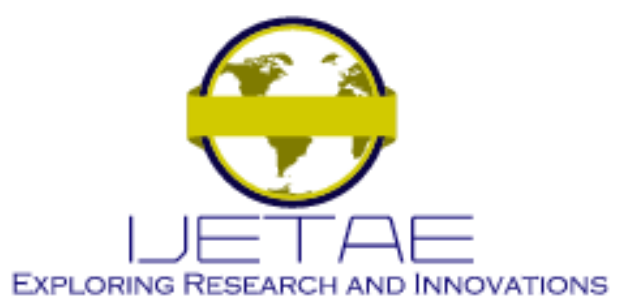

International Journal of Emerging Technology and Advanced Engineering

Website: www.ijetae.com (E-ISSN 2250-2459, Scopus Indexed, ISO 9001:2008 Certified Journal, Volume 11, Issue 12, December 2021)

A multi-level perspective is used to connect the science and technology perspective with economics studies. It is also necessary to explore, revisit, and evaluate a particular transition development aspect [86].

The TVWS implementation assessment tool in the appendix is based on the proposed architecture framework for architecting technology transition, shown in Figure 2. The technological transition architecture framework was proposed in [40] by Davis et al. that comprises seven aspects: administrative, analysis, projects, current state, future states, objectives, and stakeholders. Each aspect has one or more views which are defined in [40].

The context of the project architecture, the overview of the project's portfolio, the organization's background, even the acronyms and definitions of terms are provided in an administrative view.

Each individual project's documentation, including its design, basic information, application, process-oriented information (i.e., objective, status, lesson learned, and next process), is based on the project view. The project manager commonly uses all the information on this view to be the basis for planning and scheduling activities.

In objective aspects, both the portfolio-level and projectspecific are documented and reviewed.

Stakeholders play an essential role in each project. All the information, including the mission-vision statements, organizational charts, and biographical information, can support the analysis view to assess the stakeholders' position based on their objectives, policies, and regulations.

All the distinct characteristics of the niche, regime, and landscape are documented in the current state aspect. The current niche view includes the full description of the project's capabilities, benefits, and limitations. Current regimes document the dominant technological characteristic in users and industry. The current landscape documents current significant ongoing trends. The current niche and current regimes in terms of market, economic, political, cultural, and demographic factors are also documented in this view. All the information in the current state becomes the basis in the analysis view.

Future state views are based on the current state view counterparts. However, the desired outcomes and expected states are documented in this view.

Analysis views are subdivided into six parts: the benefits and limitations, supply and demand, policy and regulations, niche-regime analysis, niche-landscape analysis, and regime-landscape analysis.
The benefits and limitation aspects document the project's benefits, and limitations, including its current application and future benefits, are determined. The supply and demand aspects document the sources, constraints, current or potential supply, and demand issues to compete in the market. The policy and regulation aspects identify the policies and regulations that can support an emerging technology. The policies and regulations impact the current niche, current or dominant regimes, and even the technological landscape. Some policies may support the current niche or may challenge the dominant regimes and the technological landscape.

The niche-regime analysis view documents the relationship between niche technology and dominant technology. In some cases, the niche technology serves as an add-on to the current dominant technology. However, sometimes, niche technology completely replaces the current dominant technology. The niche-landscape analysis view also documents the opportunity to fit the current niche technology in the current landscape. The cultural biases, economic conditions, and shifting political or market conditions are used for further iterations of the project's objectives and design. The regime-landscape analysis view documents the relationship between the current dominant technology and the current landscape in order to determine the factors that may affect its stability. Figure 1 shows the three-dimensional view of the developed technological transition architecture framework [40].

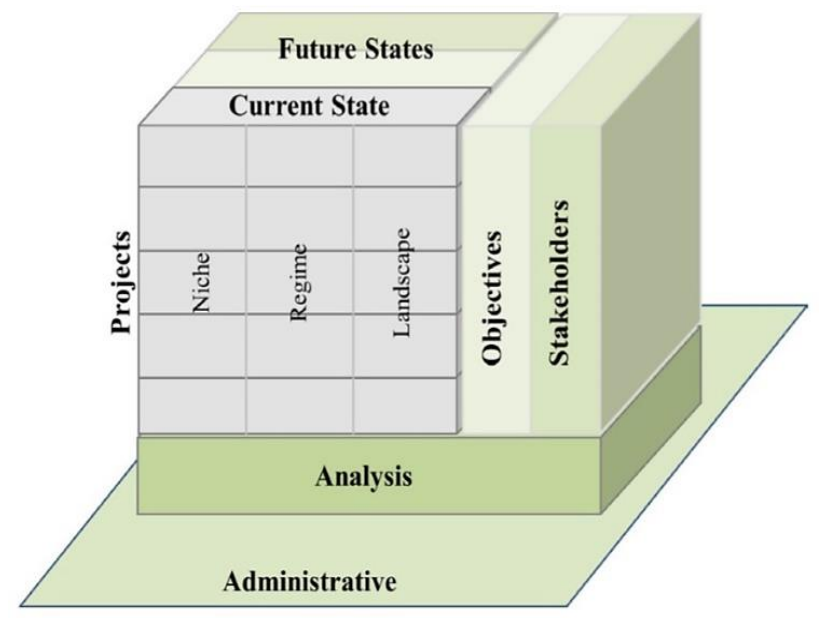

Figure 2. Technological Transition Architecture Framework [40]. 


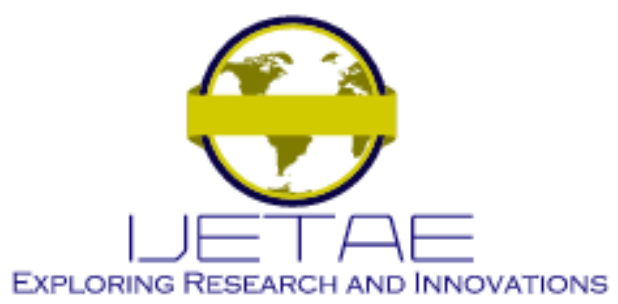

International Journal of Emerging Technology and Advanced Engineering

Website: www.ijetae.com (E-ISSN 2250-2459, Scopus Indexed, ISO 9001:2008 Certified Journal, Volume 11, Issue 12, December 2021)

\section{RESUlts AND Discussions Of THE SURVEY MATERIAL}

The development of the TVWS implementation assessment tool is based on the technological transition architecture framework. For measuring the transitions to the adoption and implementation of the TVWS system in one's country, the authors developed the questionnaire in the appendix of this paper. Each question must be rated according to the relevance of the topic in the country of interest.

Some questions must be provided with clear descriptions based on the demand. The other questions must be rated based on five levels accordingly. Level 0 pertains to refuser, no project activities, or waiting for projects. Level 1 pertains to hesitator or at least in the planning phase of the implementation or basic project activities. Level 2 means followers of implementing the technology or with the first pilot implementation or may also have intermediate project activities. Level 3 means the forerunner of implementing the project. Alternatively, it can point to some project evidence or may have advanced project activities. Furthermore, Level 4 means innovating the technological project or with best practices and various evidence of top-level projects. The survey material provides different aspects from identifying the source, project, objectives, stakeholders, current state, and future state, which leads to the analysis aspects and views.

In the administrative/organizational source, one needs to describe the company or organization and its portfolio. It includes the company profile, mission statement, and values. These descriptions are included to align the organization's goal regarding the use of TVWS in either a government or a private entity. Also, the primary and other services provided by the organization should be indicated.

The TVWS system implementation project must also have a description based on the implementations in one's country. In this field, the TVWS systems are categorized into two; the first is approved communications that use TVWS wireless channels. Second, the TVWS system is a matured system that has been adopted and is being utilized. Furthermore, the type of implementation of TVWS, whether it involves the government, industry, academe, or public-private partnership, is also considered. This assessment is beneficial to have a common understanding of the TVWS technology's current status in the country of concern.
The TVWS implementation objectives in one's country must be provided, including its short-term and long-term objectives in technical, social-economic, and environmental aspects. The stakeholder's objectives must also be provided where the short-term objective is less than or equal to a five-year time horizon while the long-term comprises objectives greater than five years. Stakeholders are also classified into primary and secondary, where the level of involvement and their position should be considered. Primary stakeholders are the company, agency, people, or person directly involved, while the secondary is indirectly involved. The stakeholder's role in the implementation of TVWS communications in their country must be specified. In this manner, the objectives and roles of each stakeholder can be evaluated further and show the potential barriers and pathways of the current niche, regimes, and landscapes.

The current niche, regimes, and landscape must be rated according to the country's TVWS system implementation's current status. The current niche field determines if the given country has strategies with clearly defined goals and milestones. The current regime field determines if businesses, conglomerates, and other existing telecommunications companies see potential profit in implementing the TVWS system. The current landscape field determines if one's country uses the TVWS communications system as an alternative to cellular or WiFi for internet access. This current niche determines the level of TVWS strategies, market demand, and adoption for coexistence or alternative, which enables an initiative for the future vision of the technology.

The future state vision of the TVWS communications technology in their country must be described. The future niche, regime, and landscape must also be rated based on their country's implementation level. The future niche of the TVWS system in one's country measures if there is a chance of success. In the future regime, this aspect determines an increase in the number of TVWS operators in the country. Moreover, in the future, the landscape determines if the TVWS system can continue to exist like broadcast communications, cellular communications, Internet, WiFi, satellite communications, and professional radio in one's country.

The benefits and limitations, supply and demand, policy and regulations, niche-regime, niche-landscape, and regime landscape are part of the analysis view, which must also be rated according to the country's implementation level. 


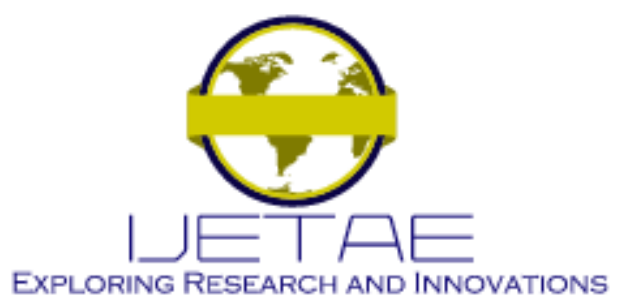

International Journal of Emerging Technology and Advanced Engineering

Website: www.ijetae.com (E-ISSN 2250-2459, Scopus Indexed, ISO 9001:2008 Certified Journal, Volume 11, Issue 12, December 2021)

The benefits and limitations field determines symbiotic technology or substitutional technology compared to cellular communications and the WiFi system in one's country. Symbiotic technology refers to the coexistence of TVWS or complementing existing and new technologies with or without integration. The technology's viability can be identified based on the level that best represents that TVWS can be both symbiotic and substitutional. The supply and demand field can measure the demand's anticipation to produce the technology's necessary supply. The policies and regulations field gauges if some policies and regulations support the TVWS system implementation and encourage healthy competition in one's country. Policies and regulations are crucial in using TVWS, hence the rating level in the material where policies exist and are updated for economic growth. The aforementioned analysis also affects the analysis since TVWS depends on the country's regulation and usage of unlicensed spectrum bands.

The niche-regime analysis determines if the TVWS system can replace the sub-GHz systems like cellular, $\mathrm{WiFi}$, satellite, or IoT to provide voice, data, or Internet access. The niche-landscape analysis determines if the cultural biases, limiting economic conditions and shifting political or market conditions can affect a country's TVWS implementation. The regime-landscape analysis is based on businesses and operators on TVWS in the country if it is perturbed by market, culture, demographics, and politics.
TABLE 2 PARAMETERS OF THE SURVEY MATERIAL

\begin{tabular}{|c|c|c|}
\hline Parameter & Description & Levels (0-4) \\
\hline $\begin{array}{l}\text { Current } \\
\text { Niche }\end{array}$ & $\begin{array}{l}\text { Measures the implementation } \\
\text { strategies with definite, distinct goals } \\
\text { and milestones }\end{array}$ & \multirow{3}{*}{$\begin{array}{l}\text { Assessment of current } \\
\text { situation and projects of } \\
\text { TVWS. Level } 4 \text { with the } \\
\text { high level of } \\
\text { implementation, strategies, } \\
\text { markets, and usage. }\end{array}$} \\
\hline $\begin{array}{l}\text { Current } \\
\text { Regime }\end{array}$ & $\begin{array}{l}\text { Provides a current analysis of potential } \\
\text { TVWS profitability for companies and } \\
\text { businesses }\end{array}$ & \\
\hline $\begin{array}{l}\text { Current } \\
\text { Landscape }\end{array}$ & $\begin{array}{l}\text { Measures the current usage of TVWS } \\
\text { as an alternative to existing wireless } \\
\text { systems such as cellular and WiFi }\end{array}$ & \\
\hline $\begin{array}{l}\text { Future } \\
\text { Niche }\end{array}$ & $\begin{array}{l}\text { Measuring the possibility of success of } \\
\text { TVWS implementation's future states }\end{array}$ & \multirow{3}{*}{$\begin{array}{l}\text { Envision of possible states, } \\
\text { potential opportunities, and } \\
\text { barriers leading to analysis } \\
\text { effort. Level } 4 \text { indicates a } \\
\text { high possibility of success, } \\
\text { increase in the number of } \\
\text { operators, and continuity. }\end{array}$} \\
\hline $\begin{array}{l}\text { Future } \\
\text { Regime }\end{array}$ & $\begin{array}{l}\text { Indicates the number of the current } \\
\text { and potential increase of TVWS } \\
\text { operators }\end{array}$ & \\
\hline $\begin{array}{l}\text { Future } \\
\text { Landscape }\end{array}$ & $\begin{array}{l}\text { Evaluation of the future continuity of } \\
\text { TVWS usage viz. cellular and WiFi } \\
\text { systems }\end{array}$ & \\
\hline $\begin{array}{l}\text { Niche- } \\
\text { Regime } \\
\text { Analysis }\end{array}$ & $\begin{array}{l}\text { Evaluation of TVWS as a possible } \\
\text { replacement to existing sub-GHz } \\
\text { systems in view of geographical usage }\end{array}$ & \multirow{3}{*}{$\begin{array}{l}\text { Measures the applicability } \\
\text { and limiting factors of } \\
\text { TVWS. Level } 4 \text { indicating } \\
\text { high number of possible } \\
\text { applications, and no } \\
\text { limiting factors. }\end{array}$} \\
\hline $\begin{array}{l}\text { Niche- } \\
\text { Landscape } \\
\text { Analysis }\end{array}$ & $\begin{array}{l}\text { Evaluation of factors affecting the } \\
\text { implementation of TVWS }\end{array}$ & \\
\hline $\begin{array}{l}\text { Regime- } \\
\text { Landscape } \\
\text { Analysis }\end{array}$ & $\begin{array}{l}\text { Evaluation of factors affecting } \\
\text { business and operators of TVWS }\end{array}$ & \\
\hline
\end{tabular}




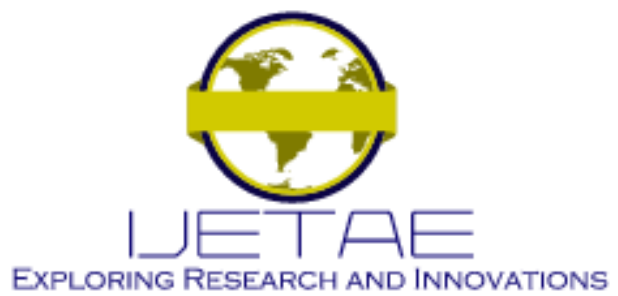

International Journal of Emerging Technology and Advanced Engineering

Website: www.ijetae.com (E-ISSN 2250-2459, Scopus Indexed, ISO 9001:2008 Certified Journal, Volume 11, Issue 12, December 2021)

The parameters and analysis of the developed survey material in gauging the sustainability of TVWS are summarized in Table 2. The bottom-up technique is applied, with an assessment of current state of TVWS leading to future probable states followed by the analysis.

The survey material developed is based on Davis's technological transition architecture framework, where the sustainability approach considers the theoretical perspectives of multi-level perspective, strategic niche management, and transition management. The use of TVWS relies heavily on policy changes in spectrum management; due to these revisions, each of the factors affecting the adaption and transitions should be considered. Hence, identifying and measuring different aspects and views from strategies, market, technological constraints, and analysis are given importance in the survey material. Finally, the framework presents the relevance of theoretical and practical needs for sustaining the development and transition of TVWS to improve communications systems.

\section{CONCLUSIONS}

There are many advantages to utilizing the TVWS communications system. Moreover, many challenges need to be adequately addressed. Some aspects of technology, especially emerging technology sometimes overlooked. Some aspects of the TVWS technological transition can be addressed based on the technological transition architecture framework using the proposed tool. Singapore, Japan, and the Philippines are considered because they adopted TVWS communications technology compared to other countries in Asia. This paper discusses their implementations and projects that show the potential use cases of TVWS. A survey material is developed based on systems engineering that can guide the technological transition of TVWS from the current and future views. To gauge the sustainability transition, the majority of the material is through rating, which bests represents the position of the country, which incites the analysis further. Also, envisioning the future state of TVWS should be specified, where both of these aspects are used to inform future decision-making and direction for the stakeholders. Using the questionnaire developed in this paper, we can gauge if the transitions towards adopting and implementing the TVWS system in the given country can be sustained.

\section{Acknowledgment}

The Sumitomo Foundation and De La Salle University are acknowledged for supporting this work.

\section{REFERENCES}

[1] Parcu, P.L., A. Nicita, G. Corda, M.A. Rossi and L.F. Bravo, 2012. Authorised shared access (ASA): An innovative model of procompetitive spectrum management; SSRN.

[2] Nychis, G., C.E. Tsourakakis, S. Seshan and P. Steenkiste, 2014 Centralized, measurement-based, spectrum management for environments with heterogeneous wireless networks., In IEEE International Symposium on New Frontiers in Dynamic Spectrum Access Networks, , pp: 303-314.

[3] Baykas, T., J. Wang, M.A. Rahman, H.N. Tran, C. Song, S. Filin, Y. Alemseged, C. Sun, G.P. Villardi, C.-S. Sum, and others, 2010. Overview of TV White Spaces: Current regulations, standards and coexistence between secondary users, In IEEE 21st International Symposium on Personal, Indoor and Mobile Radio Communications Workshops, , pp: 38-43.

[4] Kwon, Y., D.K. Park and H. Rhee, 2017. Spectrum fragmentation: Causes, measures and applications. Telecommunications Policy, 41(5): 447-459.

[5] Saint, M. and T.X. Brown, 2017. The dynamic policy license, In IEEE International Symposium on Dynamic Spectrum Access Networks, , pp: 1-9.

[6] IMDA, 2018. TV White Space; Singapore.

[7] Gim, K.S., 2012. White Range Radios: TV White Space for Super WiFi and Beyond. Power Automation.

[8] Bedogni, L., M. Di Felice and L. Bononi, 2018. Dynamic Spectrum Access for Machine to Machine Communications: Opportunities, Standards, and Open Issues. Handbook of Cognitive Radio, 1-28.

[9] Oh, S.W., Y. Ma, M.-H. Tao and E.C.Y. Peh, 2014. An overview and comparison of TV White Space regulations worldwide, In International Conference on Frontiers of Communications, Networks and Applications (ICFCNA 2014 - Malaysia), , pp: 1-6.

[10] Mirandilla-Santos, M., 2016. Philippine Broadband: A Policy Brief; The Arangkada Philippines Project, American Chamber of Commerce of the Philippines.

[11] Jopson, E.M.M. and R.A.C. Caliso, 2016. Increasing Competition in the Telecommunications Sector of the Philippines; SSRN.

[12] Struzak, R. and D. Wiecek, 2013. TV White Spaces: A Pragmatic Approach, In P. Pietrosemoli, M. Zennaro, eds., ICTP, pp: 19-34.

[13] Bettancourt, R. and J.M. Peha, 2017. Reducing spectrum use in traditional and SFN-based television for uniform and non-uniform deployments. Telecommunications Policy, 41(5-6): 498-517.

[14] Loquias, R.T., C.A.G. Hilario, M.F.D. de Guzman and J.J.S. Marciano, 2019. Quantitative Assessment of TV White Space in the Western Philippine Nautical Highway, In 2019 IEEE International Symposium on Dynamic Spectrum Access Networks (DySPAN), , pp: $1-8$.

[15] Pintor, A.L.C., M.R.S. To, J.S. Salenga, G.M. Geslani, D.P. Agpawa and M.K. Cabatuan, 2012. Spectrum survey of VHF and UHF bands in the Philippines, In TENCON 2012 IEEE Region 10 Conference, , pp: $1-6$.

[16] Abitbol, M. and P.-J. Muller, 2014. "Licensed Shared Access" an innovation in European radio spectrum policy, In IEEE International Symposium on Dynamic Spectrum Access Networks, , pp: 259-262.

[17] Ishizu, K., 2015. TV White Space Technologies and Social Deployments, In ASEAN IVO Forum, 


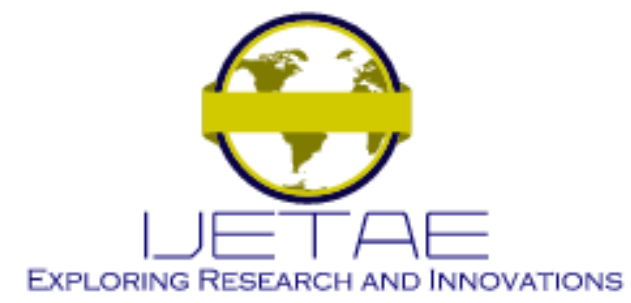

International Journal of Emerging Technology and Advanced Engineering

Website: www.ijetae.com (E-ISSN 2250-2459, Scopus Indexed, ISO 9001:2008 Certified Journal, Volume 11, Issue 12, December 2021)

[18] Harada, H., 2014. White Space Communication Systems: An Overview of Regulation, Standardization and Trial. IEICE Transactions on Communications, E97.B: 261-274.

[19] 2015. ISO/IEC/IEEE International Standard - Information technology - Telecommunications and information exchange between systems - Local and metropolitan area networks - Specific requirements - Part 11: Wireless LAN medium access control (MAC) and physical layer (PHY) specifications AMENDMENT 5. ISO/IEC/IEEE 8802-11:2012/Amd.5:2015(E) (Adoption of IEEE Std 802.11af-2014), 1-204.

[20] 2012. ECMA-392: MAC and PHY for operation in TV white space. IS0/IEC 16504, 1-190.

[21] 2011. IEEE Standard for Architectural Building Blocks Enabling Network-Device Distributed Decision Making for Optimized Radio Resource Usage in Heterogeneous Wireless Access Networks Amendment 1: Architecture and Interfaces for Dynamic Spectrum Access Networks in White Space Frequency Bands. IEEE Std 1900.4a-2011 (Amendment to IEEE Std 1900.4-2009), 1-99.

[22] 2016. IEEE Standard for Radio Interface for White Space Dynamic Spectrum Access Radio Systems Supporting Fixed and Mobile Operation. IEEE Std 1900.7-2015, 1-67.

[23] 2020. IEEE Standard - Information TechnologyTelecommunications and information exchange between systemsWireless Regional Area Networks-Specific requirements-Part 22: Cognitive Wireless RAN MAC and PHY specifications: Policies and Procedures for Operation in the Bands that Allow Spectrum Sharing where the Communications Devices May Opportunistically Operate in the Spectrum of Primary Service - Redline. IEEE Std 802.22-2019 (Revision of IEEE Std 802.22-2011) - Redline, 1-2135.

[24] 2018. IEEE Draft Standard for Information Technology Telecommunications and Information Exchange Between Systems Local and Metropolitan Area Networks - Specific Requirements Part 19: Wireless Network Coexistence Methods. IEEE P802.19.12018/D3.0, June 2018, 1-463.

[25] Chen, V., S. Das, L. Zhu, J. Malyar and P. McCann, 2015. Protocol to Access White-Space (PAWS) Databases. IETF RFC 7545.

[26] Wang, W., J. Gao and Y. Bai, 2013. Non-contiguous channel bonding via NC-OFDM for using TV white spaces, In 2013 3rd International Conference on Consumer Electronics, Communications and Networks, , pp: 427-430.

[27] Doré, J., D. Kténas, X. Popon, D. Dassonville and P. Rosson, 2018. TVWS Field Trials with BF-OFDM, In Proc. European Conf. Networks and Communications (EuCNC), , pp: 304-9.

[28] Xiao, J., R.Q. Hu, Y. Qian, L. Gong and B. Wang, 2013. Expanding LTE network spectrum with cognitive radios: From concept to implementation. IEEE Wireless Communications, 20(2): 12-19.

[29] Ye, Y., D. Wu, Z. Shu and Y. Qian, 2016. Overview of LTE Spectrum Sharing Technologies. IEEE Access, 4: 8105-8115.

[30] Stine, J.A., 2005. Spectrum management: the killer application of ad hoc and mesh networking, In IEEE International Symposium on New Frontiers in Dynamic Spectrum Access Networks, , pp: 184193.

[31] Bahrak, B., A. Deshpande, M. Whitaker and J.-M. Park, 2010. BRESAP: A policy reasoner for processing spectrum access policies represented by binary decision diagrams, In IEEE Symposium on New Frontiers in Dynamic Spectrum, pp: 1-12.
[32] Mazur, C., M. Contestable, G. Offer and N. Brandon, 2012. Comparing electric mobility policies to transition science: Transition management already in action?, In IEEE International Conference on Sustainable Energy Technologies (ICSET), , pp: 123-128.

[33] Nyasulu, T., D.H. Crawford and C. Mikeka, 2018. Malawi's TV white space regulations:: A review and comparison with FCC and Ofcom regulations, In 2018 IEEE Wireless Communications and Networking Conference (WCNC), , pp: 1-6.

[34] ETSI, 2014. White Space Devices (WSD); Wireless Access Systems operating in the $470 \mathrm{MHz}$ to $790 \mathrm{MHz}$ TV broadcast band; Harmonized EN covering the essential requirements of article 3.2 of the R\&TTE Directive; ETSI EN 301598 V1.1.1.

[35] Geels, F.W., 2002. Technological transitions as evolutionary reconfiguration processes: a multi-level perspective and a case-study. Research Policy, 31(8-9): 1257-1274.

[36] Geels, F.W. and J. Schot, 2007. Typology of socio-technical transition pathways. Research Policy, 36(3): 399-417.

[37] Ting, C., S.S. Wildman and J.M. Bauer, 2005. Government policy and the comparative merits of alternative governance regimes for wireless services, In IEEE International Symposium on New Frontiers in Dynamic Spectrum Access Networks, , pp: 401-419.

[38] Davis, K., T. Mazzuchi and S. Sarkani, 2011. Application of systems engineering methodologies to transitions to sustainable technologies: An architecture framework supporting management of portfolios of sustainable technology transition projects, In IEEE International Technology Management Conference, , pp: 201-205.

[39] Smith, A. and R. Raven, 2012. What is protective space? Reconsidering niches in transitions to sustainability. Research Policy, 41(6): 1025-1036.

[40] Davis, K., T. Mazzuchi and S. Sarkani, 2013. Architecting technology transitions: A sustainability-oriented socio-technical approach. Systems Engineering, 16(2): 193-212.

[41] Nakamura, H. and Y. Kajikawa, 2016. Transition management of a risky technology: Case of small unmanned aerial vehicles, In Portland International Conference on Management of Engineering and Technology (PICMET), IEEE, pp: 1295-1302.

[42] Cui, L., M.B. Weiss, B. Morel and D. Tipper, 2017. Risk and decision analysis of dynamic spectrum access. Telecommunications Policy, 41(5-6): 405-421.

[43] de Vries, J.P., 2017. Risk-informed interference assessment: A quantitative basis for spectrum allocation decisions. Telecommunications Policy, 41: 434-446.

[44] PCAST, 2012. Report to the President Realizing the full potential of government-held spectrum to spur economic growth; Executive Office of the (US) President, President's Council of Advisors on Science and Technology.

[45] Mustonen, M., M. Matinmikko, O. Holland and D. Roberson, 2017. Process model for recent spectrum sharing concepts in policy making. Telecommunications Policy, 41(5-6): 391-404.

[46] Freyens, B.P. and S. Alexander, 2015. Policy objectives and spectrum rights for future network developments, In IEEE International Symposium on Dynamic Spectrum Access Networks, , pp: 229-240.

[47] Song, H.S., T. Kim and T. Kim, 2017. The impact of spectrum policies on the secondary spectrum market: A system dynamics approach. Telecommunications Policy, 41(5-6): 460-472.

[48] European Commission, 2011. Report on Collective Use of Spectrum (CUS) and other spectrum sharing approaches; RSPG11. 


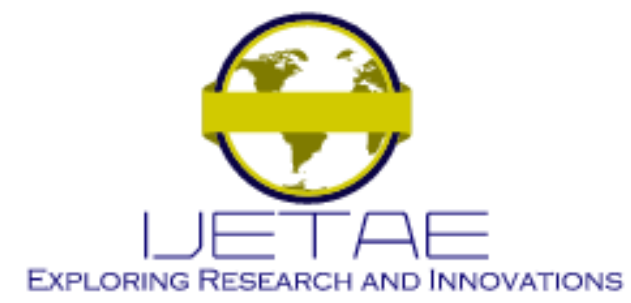

International Journal of Emerging Technology and Advanced Engineering

Website: www.ijetae.com (E-ISSN 2250-2459, Scopus Indexed, ISO 9001:2008 Certified Journal, Volume 11, Issue 12, December 2021)

[49] Yrjola, S., M. Matinmikko, P. Ahokangas and M. Mustonen, 2016. Licensed Shared Access to spectrum. Spectrum Sharing in Wireless Networks: Fairness, Efficiency, and Security, 139:.

[50] Weber, K.M. and H. Rohracher, 2012. Legitimizing research, technology and innovation policies for transformative change: Combining insights from innovation systems and multi-level perspective in a comprehensive 'failures' framework. Research Policy, 41(6): 1037-1047.

[51] Paraskevopoulou, E., 2012. Non-technological regulatory effects: Implications for innovation and innovation policy. Research Policy, 41(6): 1058-1071.

[52] Hunsucker, J.L., J.S. Law and R.W. Sitton, 1988. Transition management-a structured perspective. IEEE Transactions on Engineering Management, 35(3): 158-166.

[53] Anabi, K.H., R. Nordin and N.F. Abdullah, 2016. Database-Assisted Television White Space Technology: Challenges, Trends and Future Research Directions. IEEE Access, 4: 8162-8183.

[54] Dynamic Spectrum Alliance, www.dynamicspectrumalliance.org/pilots.html. .

[55] Chen, V., S. Das, L. Zhu, J. Malyar and P. McCann, 2015. Protocol to Access White-Space (PAWS) Databases. IETF RFC 7545.

[56] Letaief, K.B. and W. Zhang, 2009. Cooperative communications for cognitive radio networks. Proceedings of the IEEE, 97(5): 878-893.

[57] Almantheri, H.M., K.A. Amri, Y.A. Bahri and G.A. Rahbi, 2018. TV White Space (TVWS) trial in Oman: Phase one (Technical), In Proc. and Wireless Communications (DINWC) 2018 Sixth Int. Conf. Digital Information, Networking, , pp: 1-6.

[58] Rupasinghe, N. and İ. Güvenç, 2014. Licensed-assisted access for WiFi-LTE coexistence in the unlicensed spectrum, In IEEE Globecom Workshops, , pp: 894-899.

[59] Schramm, R., J. Lauterjung, S. Stavrou and E. Charalambous, 2012. Testbed for coexistence evaluation in TV White Spaces, In 2012 Future Network Mobile Summit (FutureNetw), , pp: 1-6.

[60] Dinh, C.H. and P.V. Tien, 2014. Assessment of TV white space in Vietnam, In 2014 International Conference on Advanced Technologies for Communications (ATC 2014), , pp: 637-640.

[61] Roper, S. and S. Arvanitis, 2012. From knowledge to added value: A comparative, panel-data analysis of the innovation value chain in Irish and Swiss manufacturing firms. Research Policy, 41(6): 10931106.

[62] Cave, M. and R. Nicholls, 2017. The use of spectrum auctions to attain multiple objectives: Policy implications. Telecommunications Policy, 41(5-6): 367-378.

[63] http://www.imda.gov.sg/regulations-and-licensing-listing/spectrummanagement-and-coordination/spectrum-planning. Accessed November 27, 2019.

[64] Peh, E.C.Y., S.W. Oh, Y. Ma, M.-H. Tao and Y. Pei, 2015. Pricing Model for TV White Spaces Channels With Different Priorities. IEEE Wireless Communications Letters, 4(4): 401-404.

[65] Cambini, C. and N. Garelli, 2017. Spectrum fees and market performance: A quantitative analysis. Telecommunications Policy, 41(5-6): 355-366.

[66] Kuroda, T. and M. del P.B. Forero, 2017. The effects of spectrum allocation mechanisms on market outcomes: Auctions vs beauty contests. Telecommunications Policy, 41(5-6): 341-354.
[67] Kondo, R., 2015. Lecture 4: Broadcasting Technology Policies in Japan, Ministry of Internal Affairs and Communications, In SET Thirty Meet. Nat. Assoc. Broadcast. Sh., .

[68] NTC, 2017. Allowing the use of Unassigned and Unused Allocated TV Broadcast Channels (TV White Space) on Secondary and NonInterference Basis; Philippines Memo. Circ. No. 02-04- 2017.

[69] Patalinghug, E. and J. Patalinghug, 2017. What Does Improved Spectrum Management Mean for the Philippines?; SSRN.

[70] DOST, 2014. TV White Space Deployment in PH the Largest in Asia; Philippines, DOST-ICTO Press Release. December.

[71] DICT, 2017. National Broadband Plan, Philippines.

[72] Safarzyńska, K., K. Frenken and J.C. van den Bergh, 2012. Evolutionary theorizing and modeling of sustainability transitions. Research Policy, 41(6): 1011-1024.

[73] Paredis, E., 2011. Sustainability transitions and the nature of technology. Foundations of Science, 16(2-3): 195-225.

[74] Jørgensen, U., 2012. Mapping and navigating transitions-The multi-level perspective compared with arenas of development. Research Policy, 41(6): 996-1010.

[75] Rotmans, J., R. Kemp and M. Van Asselt, 2001. More evolution than revolution: transition management in public policy. Foresight, 3(1): 15-31.

[76] Kasper, I.F., 1991. Transition/integration engineering: the program management TIE between developer and user, In Technology Management: The New International Language, , pp: 755-758.

[77] de Kock, I.H. and A.C. Brent, 2017. New insights into sociotechnical transitions: A technology management perspective, In IEEE Technology \& Engineering Management Conference (TEMSCON), IEEE, pp: 329-334.

[78] Chappin, E.J. and G.P. Dijkema, 2008. On the design of system transitions Is Transition Management in the energy domain feasible?, In IEEE International Engineering Management Conference Europe, , pp: $1-5$.

[79] Demestichas, P., G. Dimitrakopoulos and K. El Khazen, 2005. Dynamic planning and management of reconfigurable systems, In IEEE International Symposium on New Frontiers in Dynamic Spectrum Access Networks, , pp: 568-572.

[80] Anker, P., 2017. From spectrum management to spectrum governance. Telecommunications Policy, 41(5-6): 486-497.

[81] Luo, Y., L. Gao and J. Huang, 2015. Spectrum Reservation Contract Design in TV White Space Networks. IEEE Transactions on Cognitive Communications and Networking, 1(2): 147-160.

[82] Hagedoorn, J. and N. Wang, 2012. Is there complementarity or substitutability between internal and external R\&D strategies? Research Policy, 41(6): 1072-1083.

[83] García-Manjón, J.V. and M.E. Romero-Merino, 2012. Research, development, and firm growth. Empirical evidence from European top R\&D spending firms. Research Policy, 41(6): 1084-1092.

[84] Markard, J., R. Raven and B. Truffer, 2012. Sustainability transitions: An emerging field of research and its prospects. Research Policy, 41(6): 955-967.

[85] Loorbach, D., 2010. Transition management for sustainable development: a prescriptive, complexity-based governance framework. Governance, 23(1): 161-183.

[86] Coenen, L., P. Benneworth and B. Truffer, 2012. Toward a spatial perspective on sustainability transitions. Research Policy, 41(6): 968-979. 


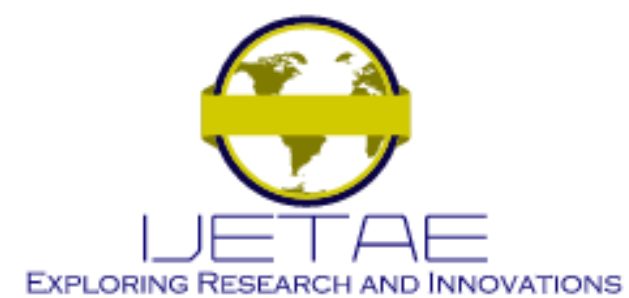

International Journal of Emerging Technology and Advanced Engineering Website: www.ijetae.com (E-ISSN 2250-2459, Scopus Indexed, ISO 9001:2008 Certified Journal, Volume 11, Issue 12, December 2021) APPENDIX: SURVEY MATERIAL

Glossary

\begin{tabular}{|c|c|}
\hline TVWS system & - is defined here as is an approved communications network that uses a TVWS wireless channel. \\
\hline $\begin{array}{l}\text { TVWS system full- } \\
\text { implementation }\end{array}$ & - here means a mature/developed TVWS system that has been adopted and is being utilized. \\
\hline Primary stakeholder & - a company, agency, people, or person directly involved in a particular organization, project, system, and the like \\
\hline Secondary stakeholder & $\begin{array}{l}\text { - a company, agency, people, or person that is indirectly involved in a particular organization, project, system, and } \\
\text { the like }\end{array}$ \\
\hline Niche & $\begin{array}{l}\text { - is defined here as a specific application for technologies where the technology/system is protected from market } \\
\text { selection pressures.* } \\
\text { - Niches provide spaces for experimenting with new technologies to explore the technology's benefits, limitations, } \\
\text { and potential applications.* }\end{array}$ \\
\hline Regime & $\begin{array}{l}\text { - is defined here as the current dominant combinations of technology and associated user practices and skill sets, } \\
\text { infrastructure, industrial and political institutions, and engineering practices* }\end{array}$ \\
\hline landscape & $\begin{array}{l}\text { - is defined here is the broader context in which niches and regimes exist* } \\
\text { - The landscape consists of slow-changing elements such as macroeconomic, demographic, cultural, and political } \\
\text { climate and trends and significant sudden events such as military conflicts or punctuated market } \\
\text { perturbations.* }\end{array}$ \\
\hline
\end{tabular}




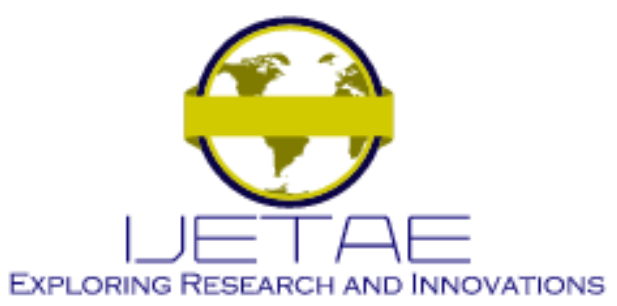

International Journal of Emerging Technology and Advanced Engineering

Website: www.ijetae.com (E-ISSN 2250-2459, Scopus Indexed, ISO 9001:2008 Certified Journal, Volume 11, Issue 12, December 2021)

0. Administrative/organizational source: Please indicate your name and affiliation information through the following three tables.

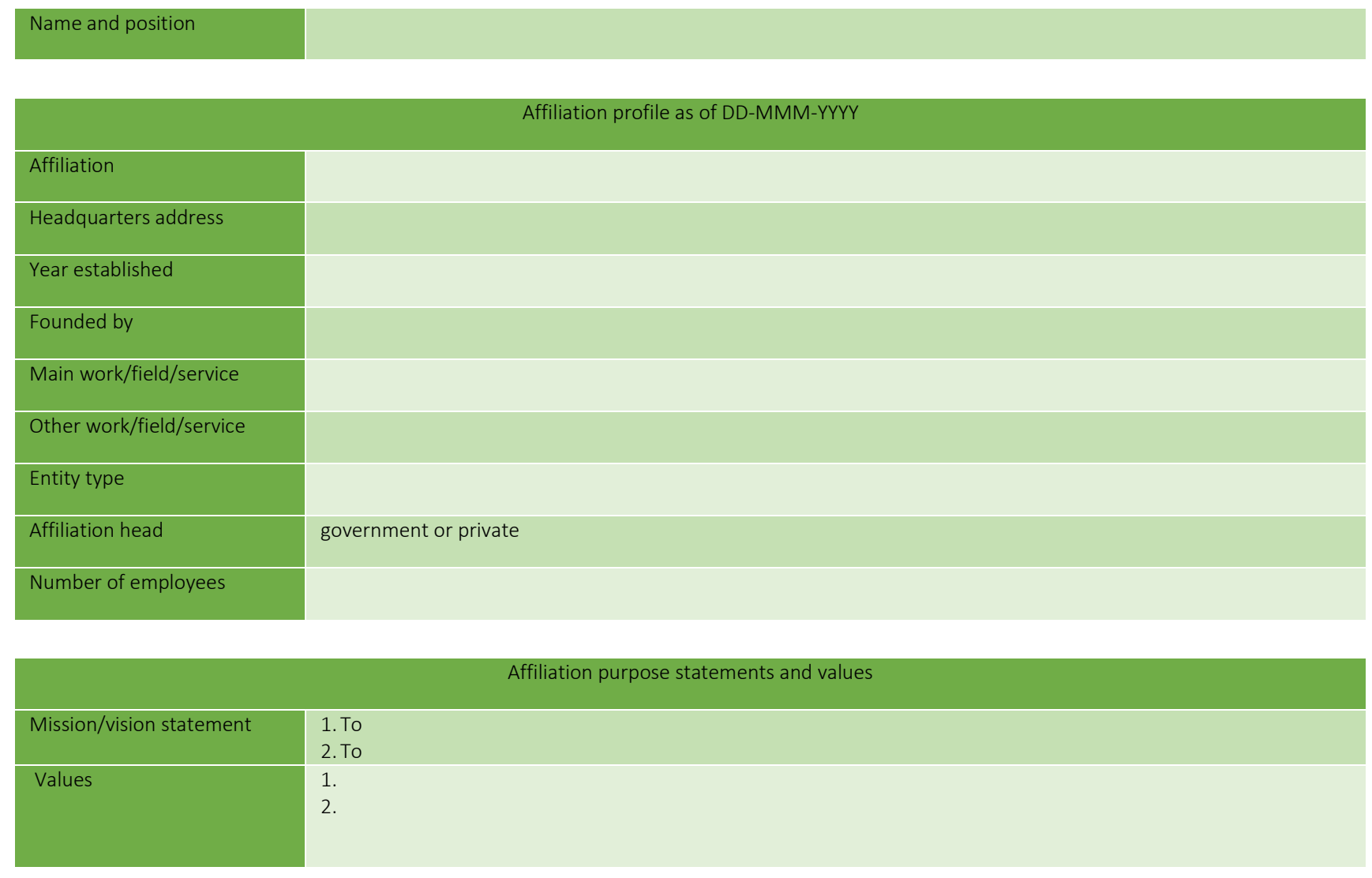

1. TVWS system implementation: Please briefly describe the implementation of a TVWS system in your country (whether done by the government, industry, academe, or public-private partnerships). Itemize the description in the table provided below instead of writing it in paragraph form.

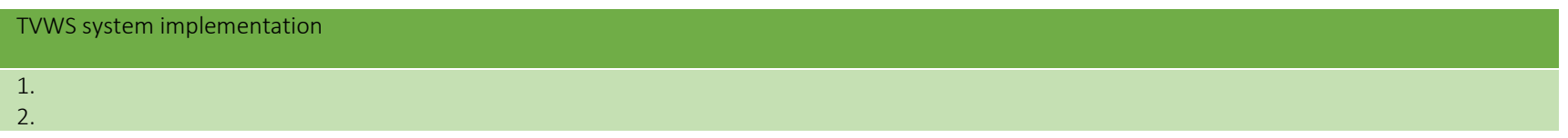

2. TVWS system implementation objectives: What were or are the objectives of the TVWS system implementation in your country in the following time horizons for social-economic and environmental impacts?

Short-term (less than or equal to 5 years) objective(s) of TVWS system implementation in your country
1. To
2. To

Long-term (greater than 5 years) objective(s) of TVWS system implementation in your country
1. To
2. To




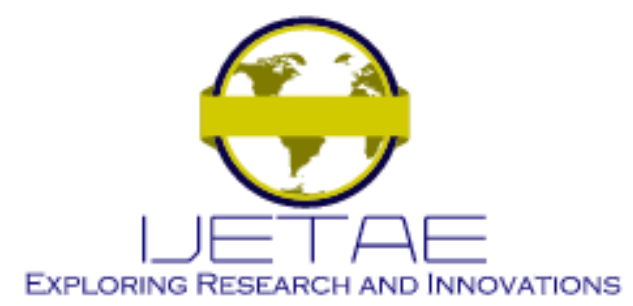

International Journal of Emerging Technology and Advanced Engineering

Website: www.ijetae.com (E-ISSN 2250-2459, Scopus Indexed, ISO 9001:2008 Certified Journal, Volume 11, Issue 12, December 2021)

3. Stakeholders: Which organization (organizations) is (are) the stakeholder (stakeholders) of TVWS system implementation in your country, what is (are) their role (roles), and what is (are) their respective TVWS system implementation objective (objectives)? Please separate the stakeholders as to whether they are primary or not.

\begin{tabular}{|l|l|}
\hline $\begin{array}{l}\text { Primary stakeholder } \\
\text { name }\end{array}$ & Role(s) \\
\hline 1. Organization 1 & $\begin{array}{l}\text { 1. To } \\
\text { 2. To }\end{array}$ \\
\hline 2. Organization 2 & 1. To \\
\hline 3. Organization 3 & 2. To \\
\hline $4 \ldots$ & 1. To \\
\hline & 2. To \\
\hline
\end{tabular}

\begin{tabular}{|l|l|}
$\begin{array}{l}\text { Secondary } \\
\text { stakeholder name }\end{array}$ & Role(s) \\
\hline 2. Organization 1 & \\
\hline 5. Organization 2 & 1. To \\
\hline 6. Organization 3 3 & 1. To \\
\hline 7.... & 2. To \\
\hline & 1. To \\
\hline & 2. To \\
\hline & 1. To \\
\hline
\end{tabular}

4. Current niches: Does your country follow a TVWS system implementation strategy with clearly defined goals and milestones? Please choose the best representative answer of your country from the following.

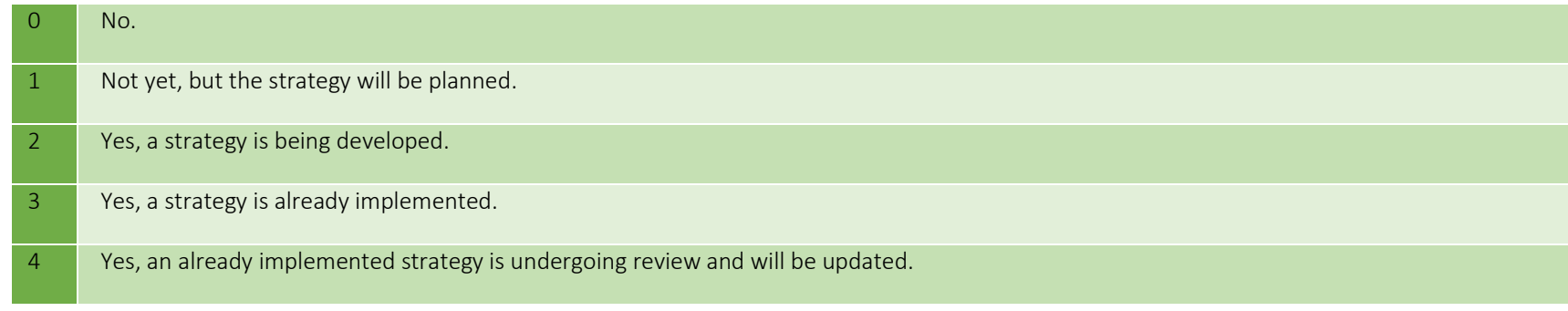

5. Current regimes: Do businesses, conglomerates, or the existing telecommunications companies in your country see potential profit in using TVWS systems? Please choose the best representative answer of your country from the following.

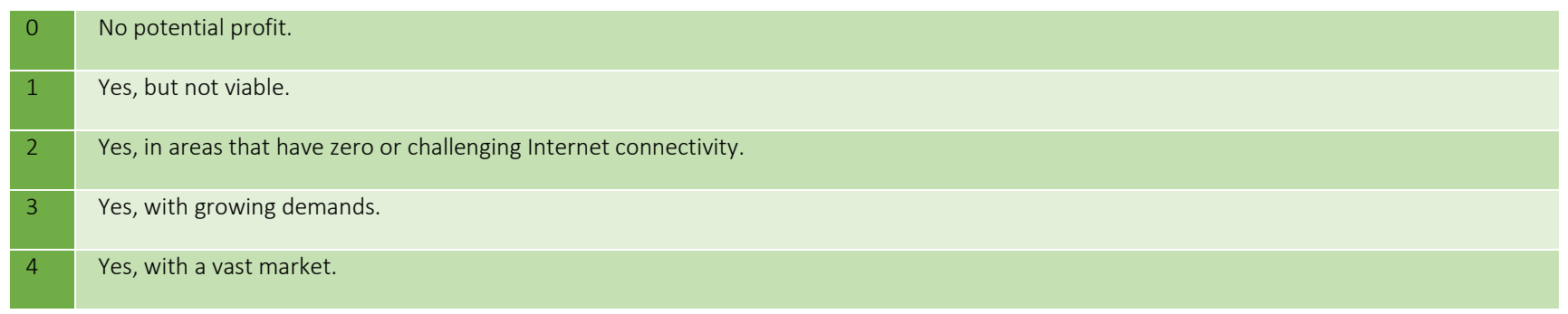




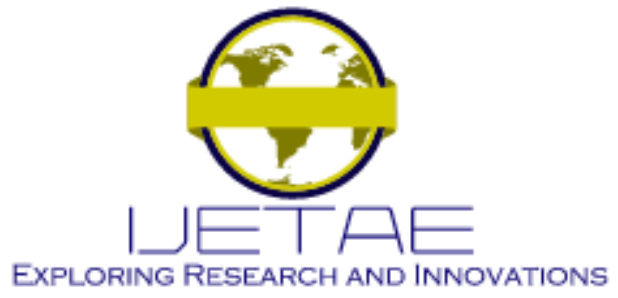

International Journal of Emerging Technology and Advanced Engineering

Website: www.ijetae.com (E-ISSN 2250-2459, Scopus Indexed, ISO 9001:2008 Certified Journal, Volume 11, Issue 12, December 2021)

6. Current landscape: Are TVWS systems being used in your country as an alternative to sub-GHz communications (cellular) or WiFi for Internet access? Please choose the best representative answer of your country from the following.

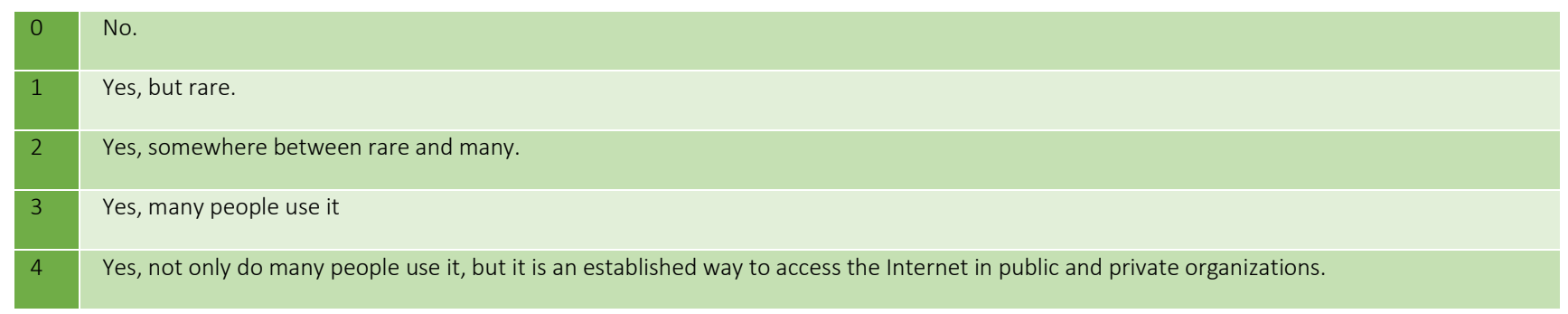

7. Future state vision: Please describe the potential future states of TVWS system implementation in your country. Please itemize them in the table provided below instead of writing them in paragraph form.

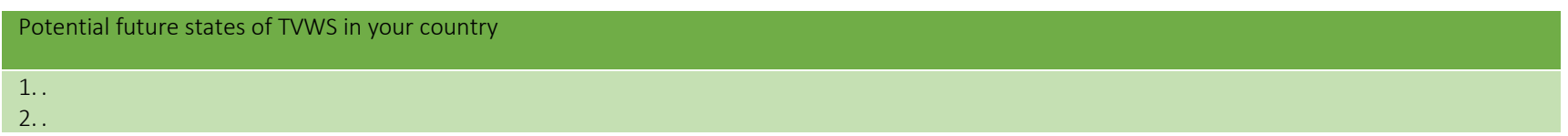

8. Future niche: What do you think is (are) the future niche (niches) of TVWS in your country and its (their) chances of success? Please itemize them in the table provided below instead of writing them in paragraph form.
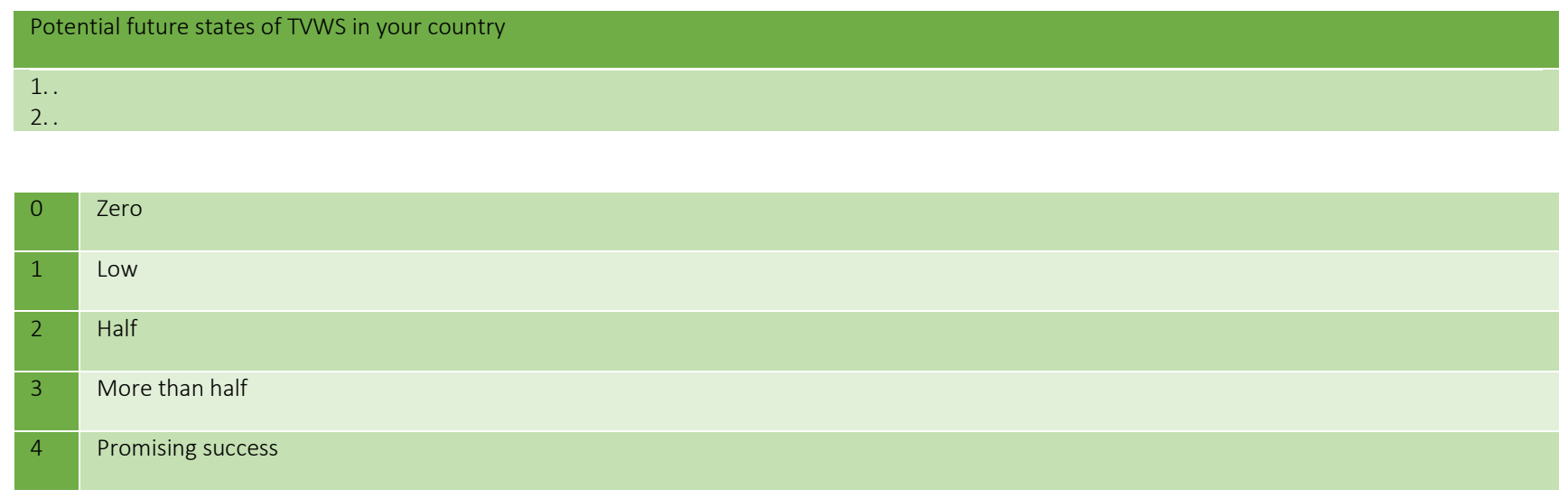

9. Future regime: Will there be an increase in the number of TVWS system operators and sub-operators (e.g., virtual network operators-like) in your country?

\begin{tabular}{|l|l|}
\hline 0 & There is no operator now, but there might be at least one (1) in the future. \\
\hline 1 & There is one (1) operator, and it is planned to be increased. \\
\hline 2 & There are two (2) operators, and it is planned to be increased. \\
\hline 3 & There are three (3) operators, and it is planned to be increased. \\
\hline 4 & There are more than three (3) operators, and it is planned to be increased. \\
\hline
\end{tabular}




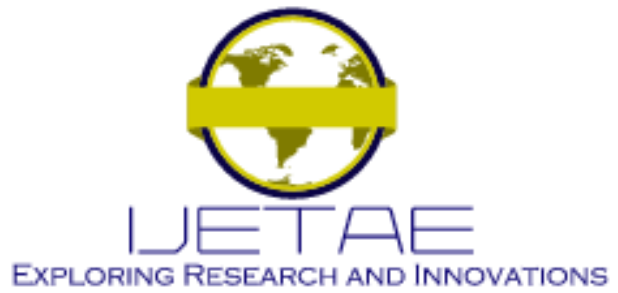

International Journal of Emerging Technology and Advanced Engineering

Website: www.ijetae.com (E-ISSN 2250-2459, Scopus Indexed, ISO 9001:2008 Certified Journal, Volume 11, Issue 12, December 2021)

10. Future landscape: Do you see TVWS systems to exist in the future and continue like current amateur radio, $\mathrm{TV} / \mathrm{AM} / \mathrm{FM} / \mathrm{SW}$ broadcasting, cellular communications, Internet, $\mathrm{WiFi}$, satellite communications, and professional radio in your country?

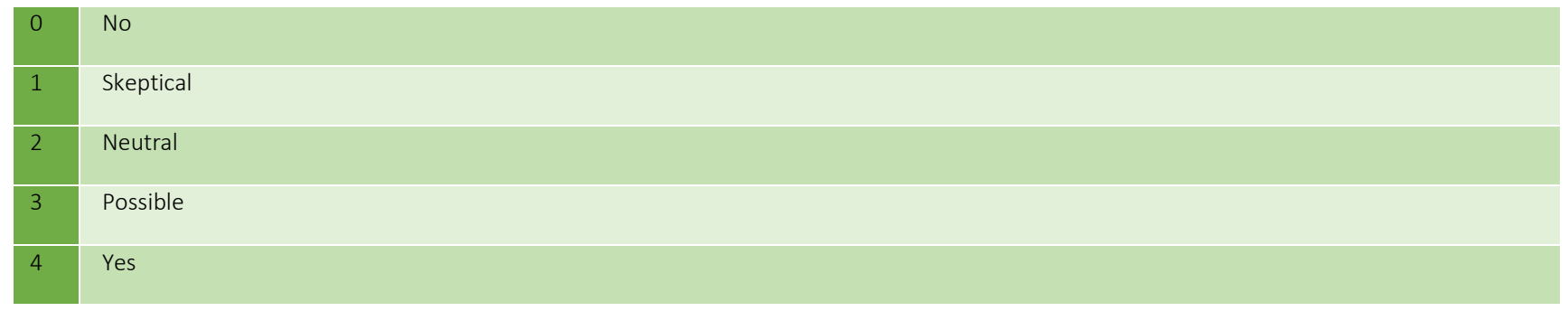

11. Benefits and limitations: How do TVWS systems' current benefits and limitations compare with cellular and WiFi systems in your country?

- Symbiotic technology: coexistence or complementarity with or without integrability of old and new technologies

- Substitutional technology: one technology entirely replaces another technology

\begin{tabular}{|l|l|}
\hline 0 & Poor: neither symbiotic nor substitutional technology \\
\hline 1 & Low: substitutional technology \\
\hline 2 & Mid: either symbiotic or substitutional technology \\
\hline 3 & High: symbiotic technology \\
\hline 4 & Best: both symbiotic and substitutional technologies \\
\hline
\end{tabular}

12. Supply and demand: Does your country anticipate the demand for TVWS systems and produce the necessary supply?

\begin{tabular}{|l|l|}
\hline 0 & It does not. \\
\hline 1 & Both supply and demand have not been measured. \\
\hline 2 & There is supply but no demand. \\
\hline 3 & There is demand but no supply. \\
\hline 4 & There is a supply for the demand. \\
\hline
\end{tabular}

13. Policy and regulations: Are there any working policies and regulations supporting TVWS systems and encouraging competition in your country?
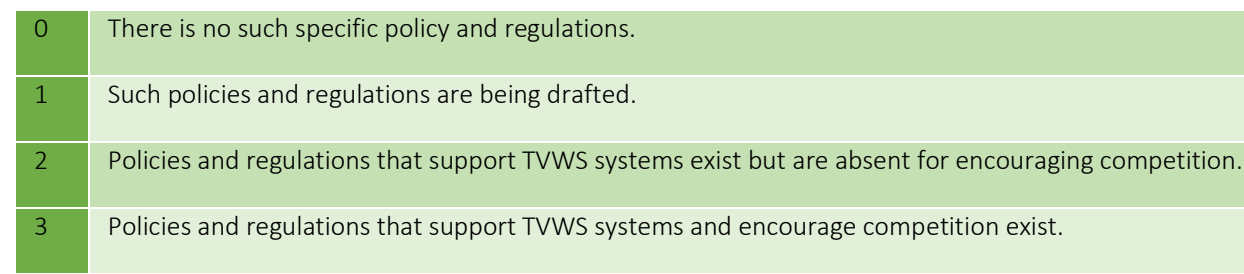


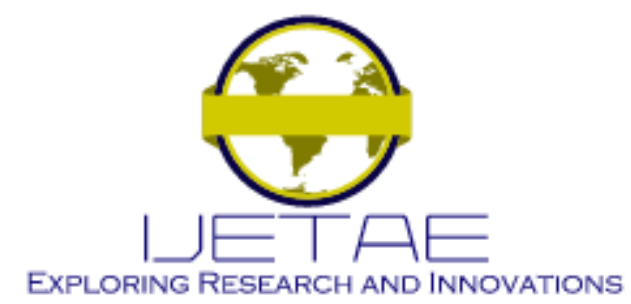

International Journal of Emerging Technology and Advanced Engineering Website: www.ijetae.com (E-ISSN 2250-2459, Scopus Indexed, ISO 9001:2008 Certified Journal, Volume 11, Issue 12, December 2021)

14. Niche-regime analysis: Could TVWS systems replace sub-GHz systems (e.g., cellular, WiFi, satellite, IoT) for providing voice, data, or Internet communications in your country?

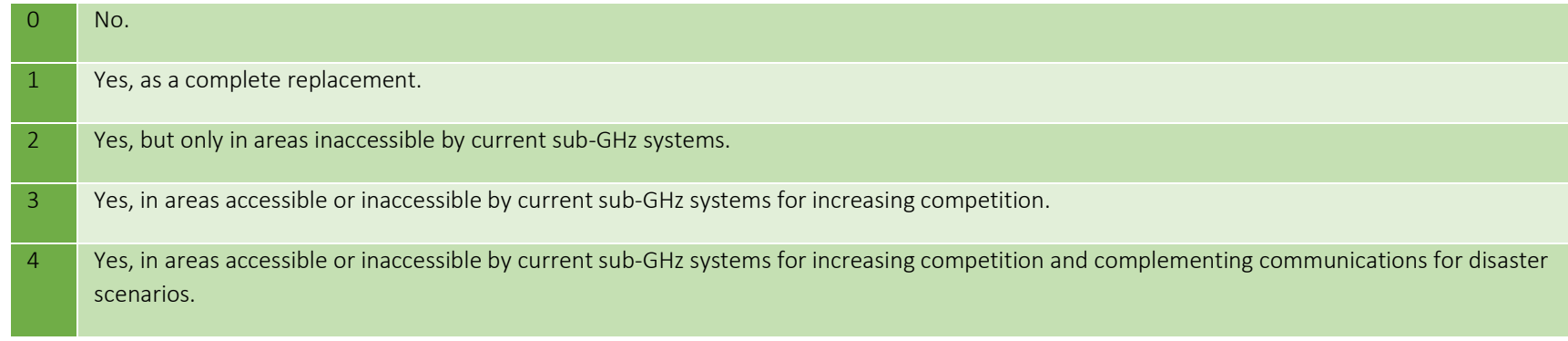

15. Niche-landscape analysis: $\quad$ Does your country have cultural biases, limiting economic conditions, shifting political or market conditions that can affect the implementation of TVWS systems in your country?

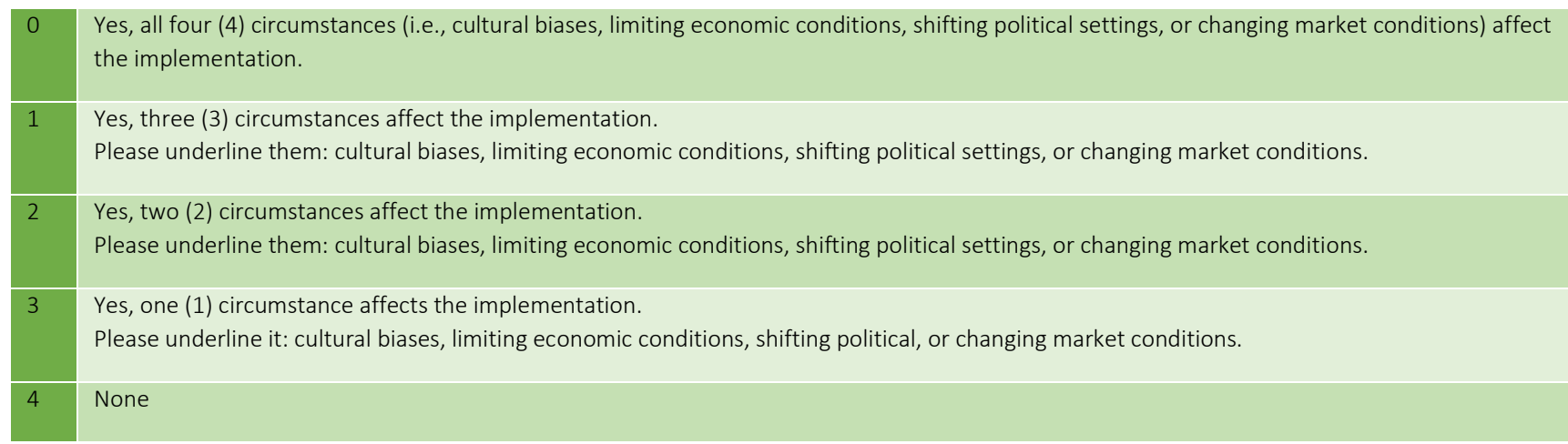

16. Regime-landscape analysis: $\quad$ Are TVWS system-based businesses and operators in your country perturbed mainly by market, culture, demographics, and politics?

\begin{tabular}{l} 
Yes, by all four (4) factors. \\
\hline 1 Yes, by three (3) factors, except (market, culture, demographics, and politics) - (please underline the exception). \\
\hline 2 Yes, by two (2) factors, except (market, culture, demographics, and politics) - (please underline the exceptions). \\
\hline 3 Yes, by one (1) factor, except (market, culture, demographics, and politics) - (please underline the exceptions). \\
No.
\end{tabular}

